Supporting Information for

\title{
Pt-Co@Pt Octahedral Nanocrystals: Enhancing Their Activity and Durability toward Oxygen Reduction with an Intermetallic Core and an Ultrathin Shell
}

Minghao Xie, ${ }^{\dagger}$ Zhiheng Lyu,$^{\dagger}$ Ruhui Chen, ${ }^{\dagger}$ Min Shen, ${ }^{\star}$ Zhenming Cao, ${ }^{\ddagger}$ and Younan Xia ${ }^{*}, \dagger$

${ }^{\dagger}$ School of Chemistry and Biochemistry, Georgia Institute of Technology, Atlanta, Georgia 30332, United States

The Wallace H. Coulter Department of Biomedical Engineering, Georgia Institute of Technology and Emory University, Atlanta, Georgia 30332, United States

*Corresponding author: younan.xia@bme.gatech.edu 

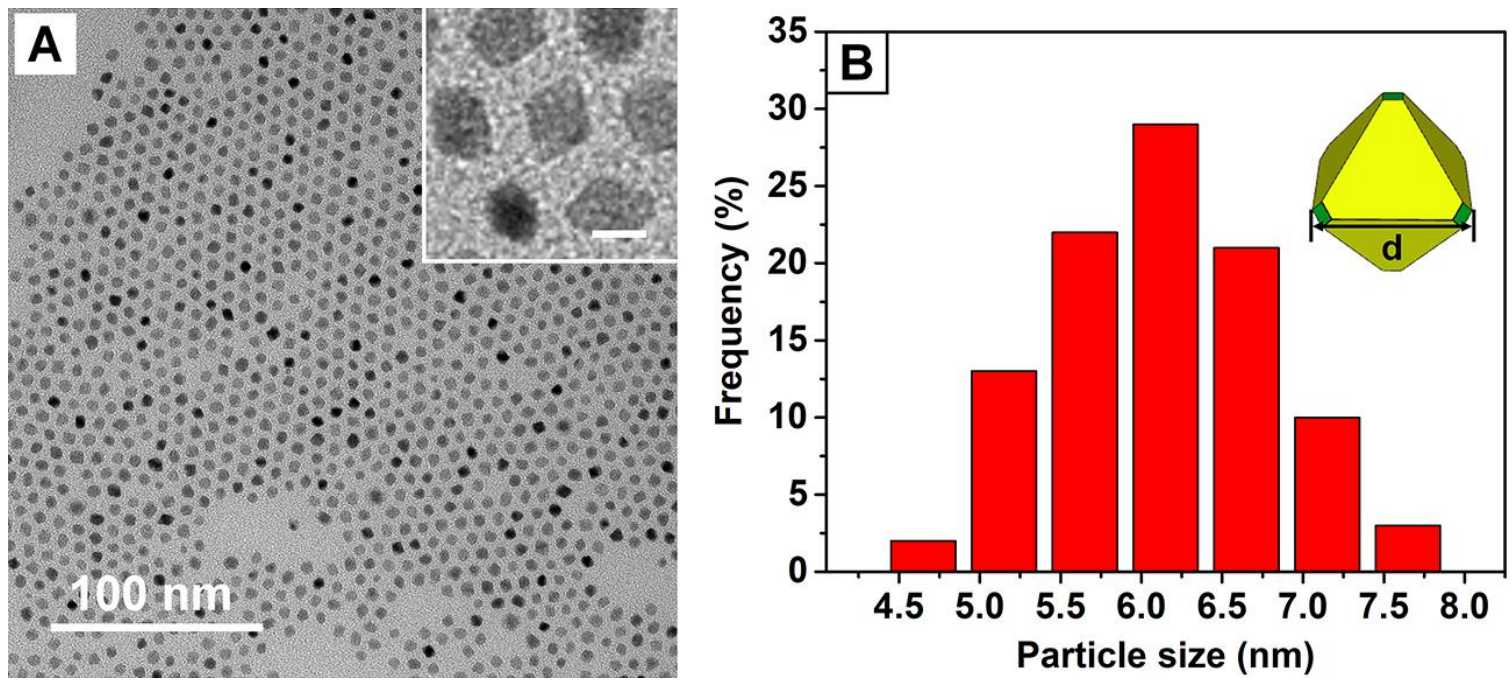

Figure. S1. (A) TEM image and (B) size distribution of the $f c c$-Pt-Co octahedral nanocrystals with an average size of $6.3 \pm 1.0 \mathrm{~nm}$. The scale bar in the inset of (A) is $5 \mathrm{~nm}$. The inset of (B) shows a schematic of the Pt-Co octahedral nanocrystal, together with the definition of size (d). 

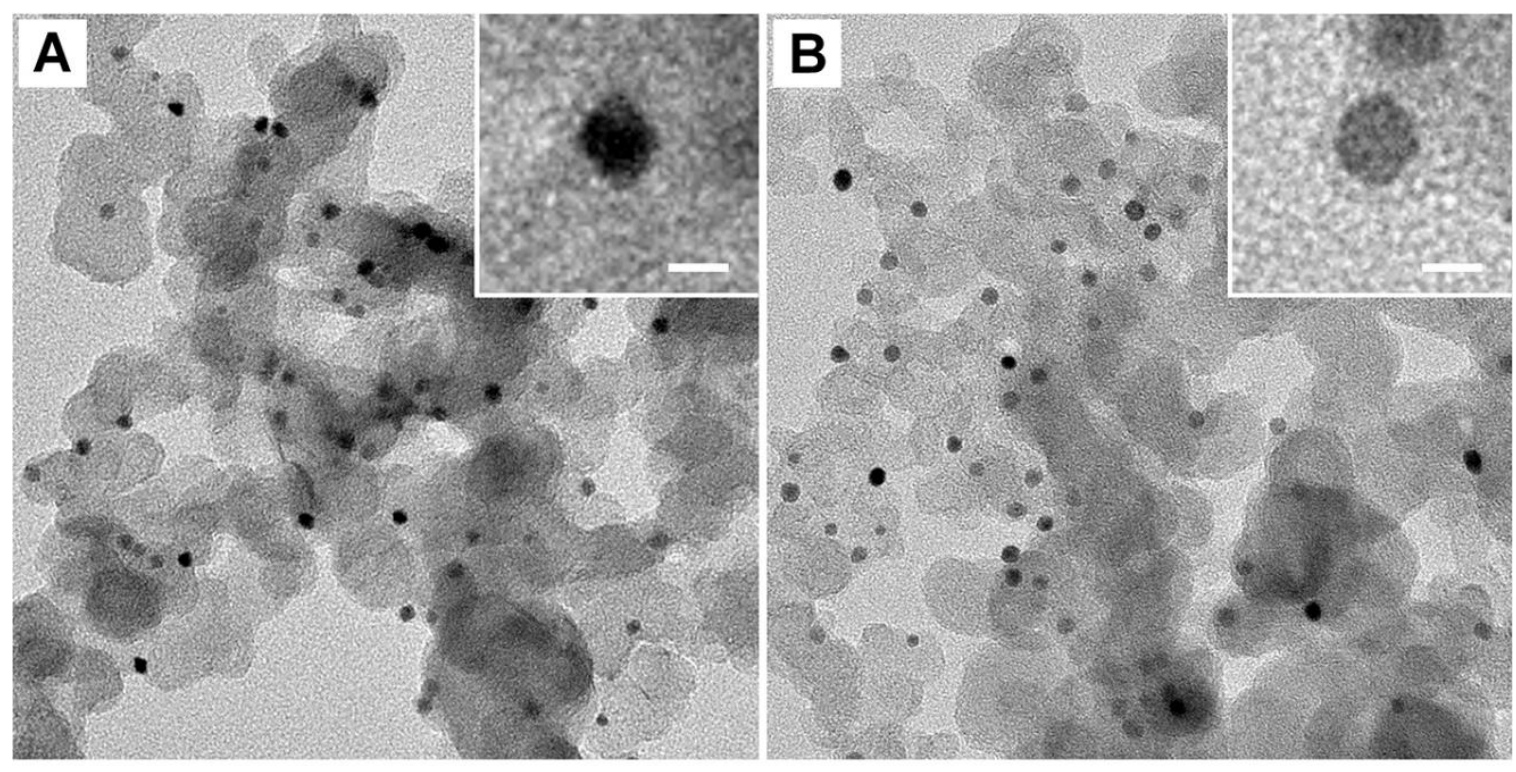

\section{$50 \mathrm{~nm}$}

Figure S2. TEM images of carbon-supported (A) $f c c$-Pt-Co octahedra and (B) $f c t$-Pt-Co truncated octahedra after annealing at $600{ }^{\circ} \mathrm{C}$ for $4 \mathrm{~h}$. The scale bars in the insets are $5 \mathrm{~nm}$. 


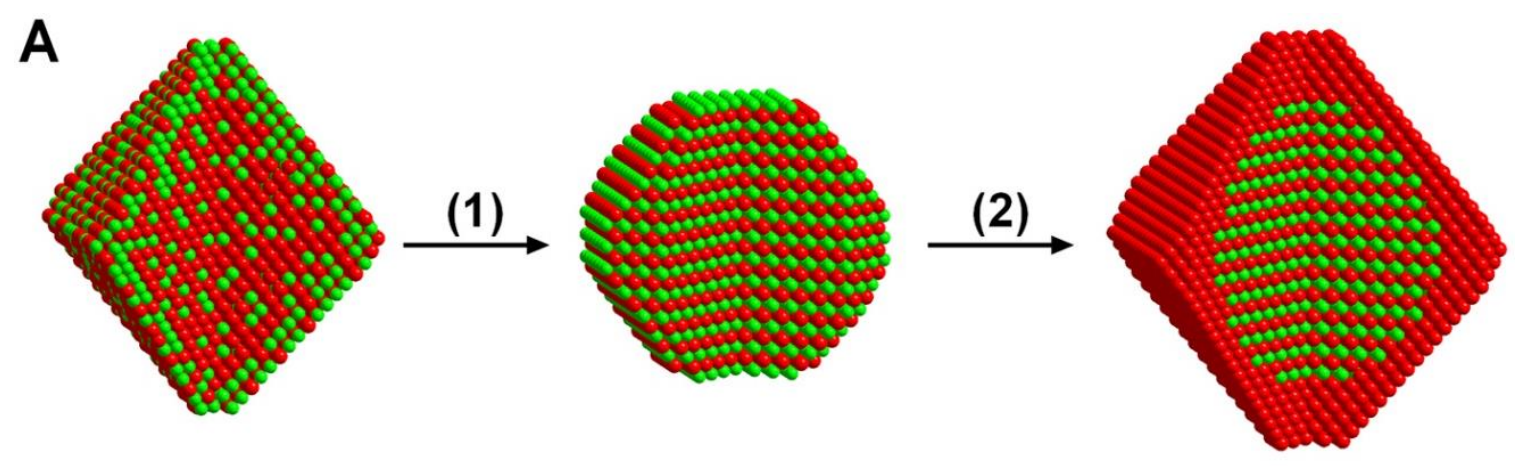

B

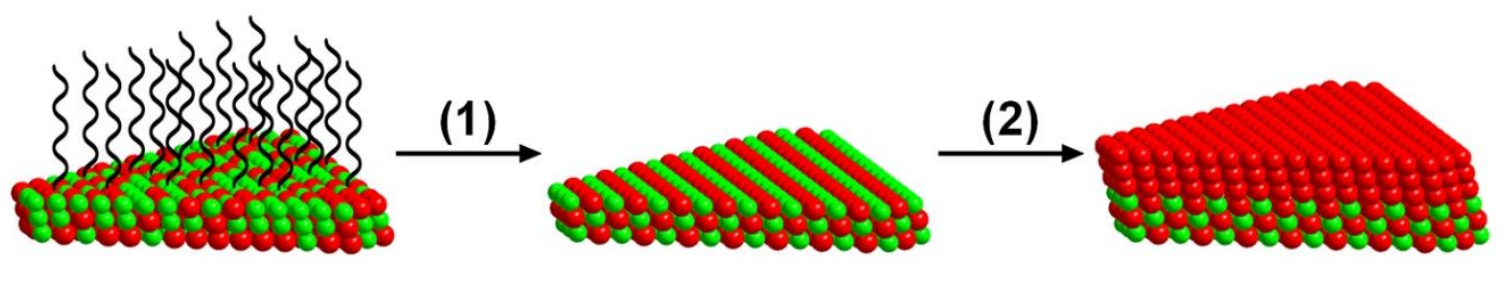

- Pt atom - Co atom 〜 Oleylamine

Figure S3. Schematic illustration showing the changes in (A) bulk and (B) surface structures when going from $f c c$-Pt-Co to $f c t$-Pt-Co@Pt nanocrystal: (1) reductive thermal annealing and (2) conformal deposition of Pt. 


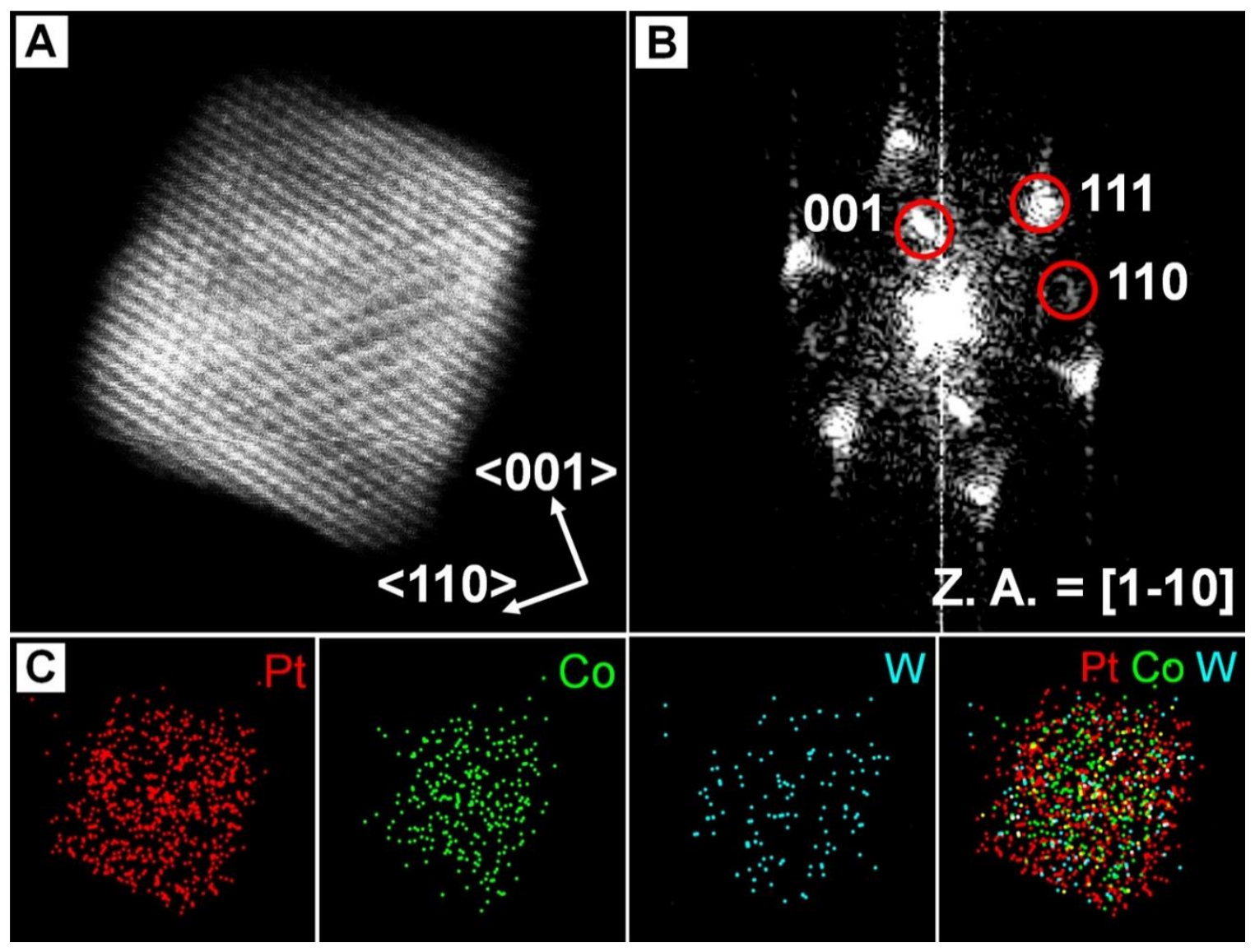

Figure S4. (A) HAADF-STEM image and (B) the corresponding FFT pattern of an individual fct-Pt-Co@Pt octahedron along [1-10] zone axis (Z. A.). (C) EDX mapping of the elements in the nanocrystal: Pt (red), Co (green), and W (cyan). 


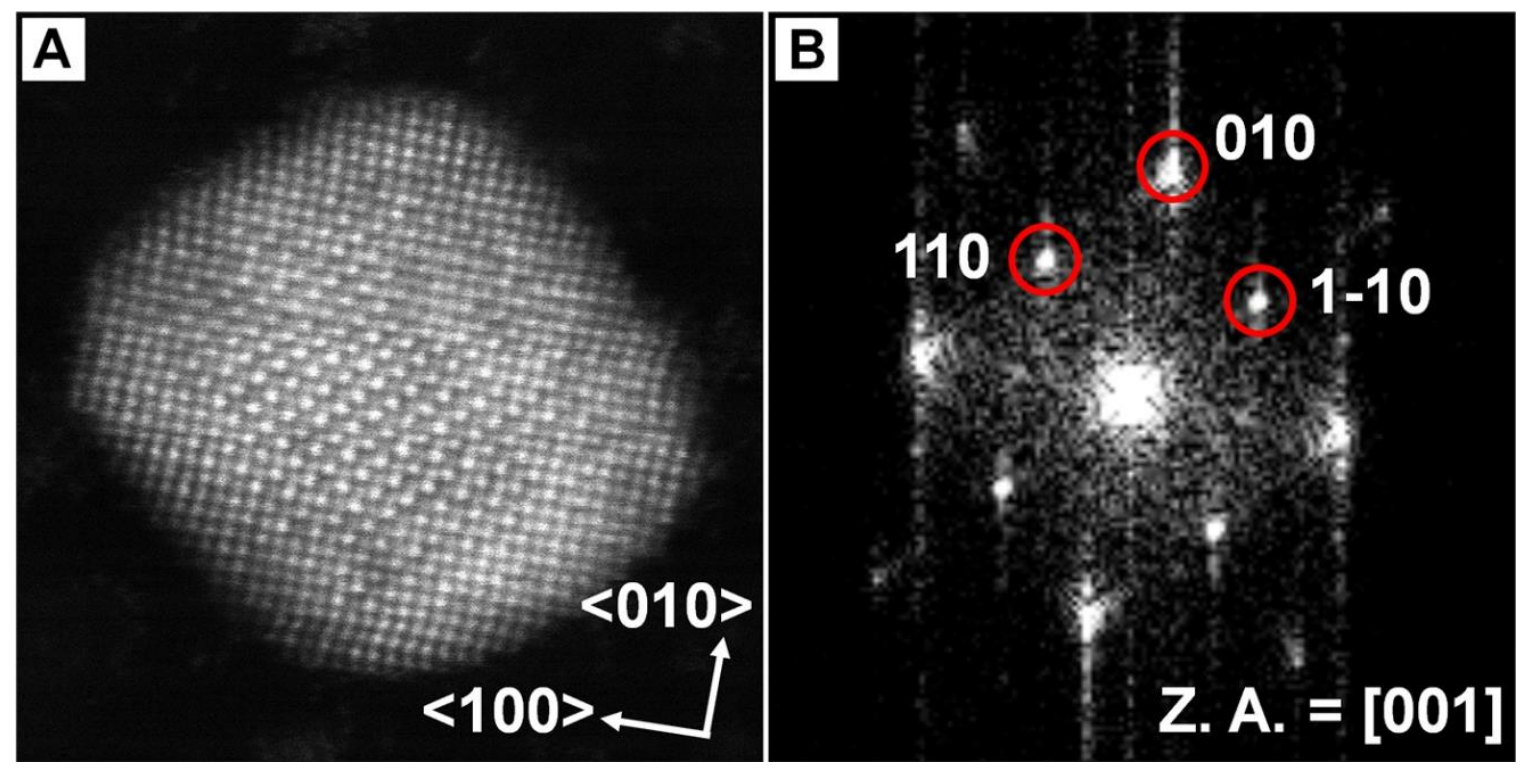

Figure S5. (A) HAADF-STEM image and (B) the corresponding FFT pattern of an individual fct-Pt-Co@Pt octahedron along [001] zone axis (Z. A.). 

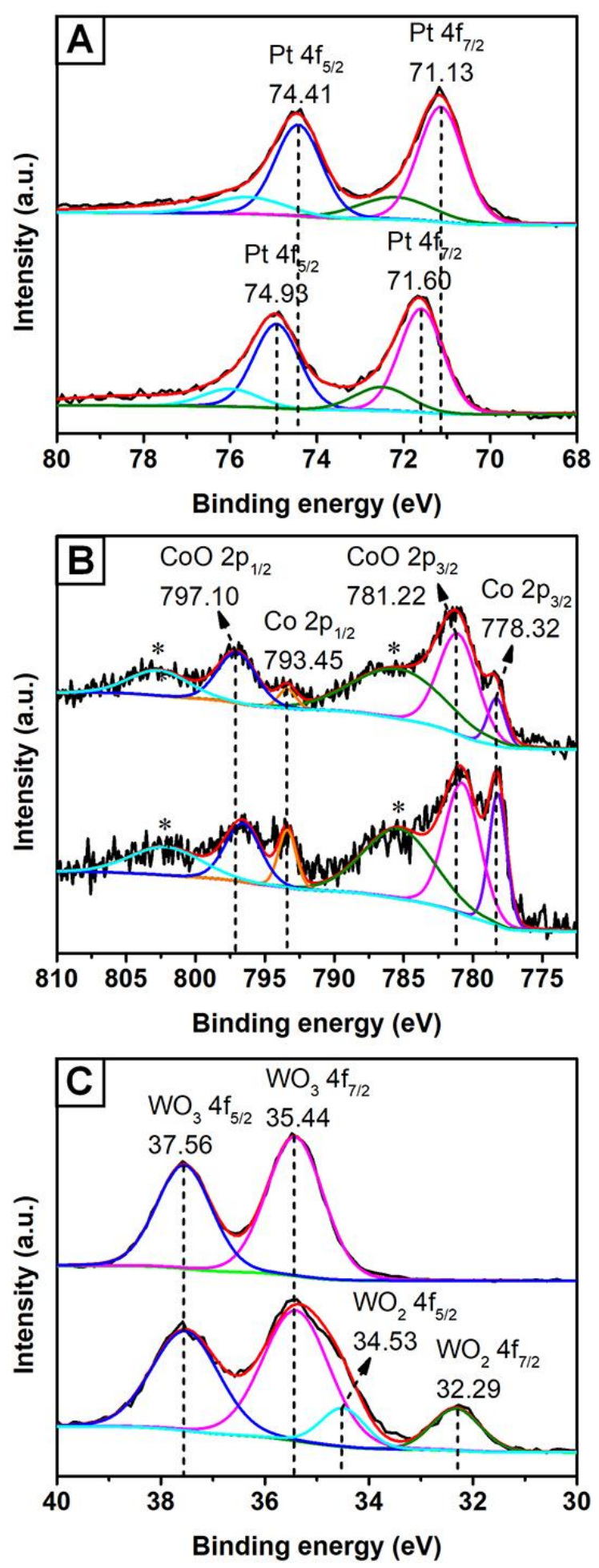

Figure S6. XPS spectra of the (A) Pt 4f, (B) Co 2p, and (C) W 4f for the $f c c$-Pt-Co octahedra (top) and $f c t$-Pt-Co truncated octahedra (bottom). The asterisks (*) in (B) indicate satellite peaks of the corresponding $\mathrm{Co} 2 \mathrm{p}$ for $\mathrm{CoO}$. 


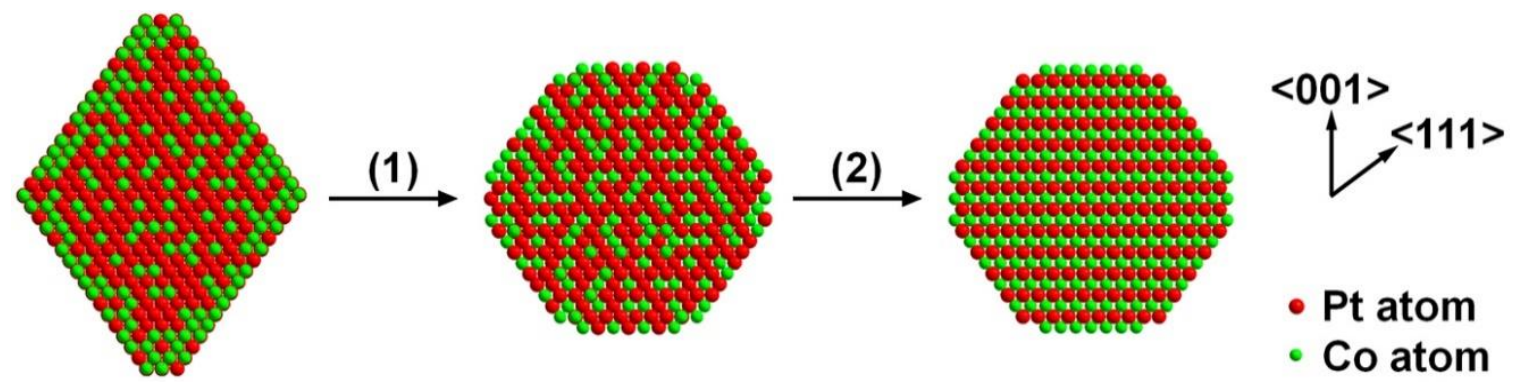

Figure S7. Schematic illustration showing the shape and phase evolution from an $f c c-\mathrm{Pt}-\mathrm{Co}$ octahedron to an $f c t$-Pt-Co truncated octahedron during the reductive annealing: (1) deformation of the octahedral shape and the interdiffusion and further alloying between Pt and Co and (2) ordering of Pt and Co atoms. 


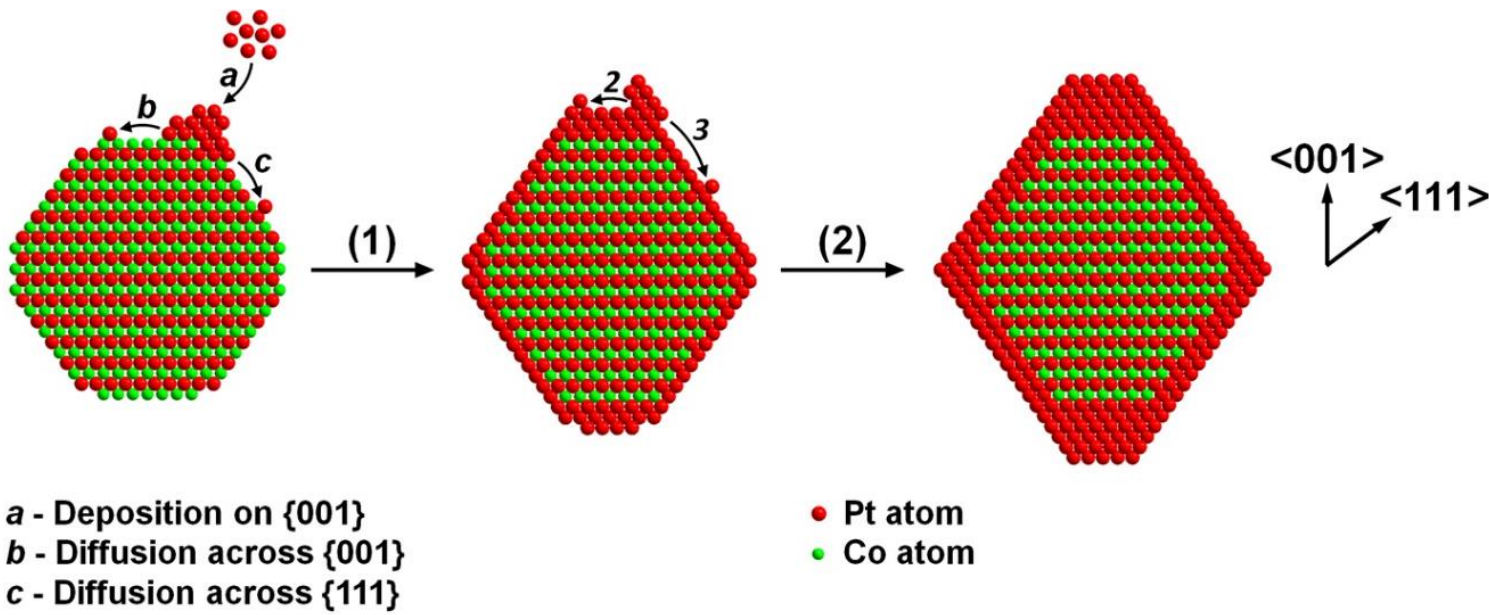

Figure S8. Schematic illustration for the synthesis of $f c t$-Pt-Co@Pt octahedral nanocrystals: (1) selective deposition of $\mathrm{Pt}$ atoms at the edge of a $\{001\}$ facet on an $f c t$-Pt-Co seed, followed by diffusion across $\{001\}$ and $\{111\}$; (2) continuous deposition of Pt atoms at the corners and edges, followed by diffusion across $\{001\}$ and $\{111\}$, yielding a fct-Pt-Co@Pt octahedral nanocrystal. 




Figure S9. TEM images of the samples prepared using the standard protocol except for: (A) the injection of the $\mathrm{Pt}(\mathrm{II})$ precursor in one shot, (B) the increase of reaction temperature from $80{ }^{\circ} \mathrm{C}$ to $95{ }^{\circ} \mathrm{C}$, (C) the injection of the $\mathrm{Pt}(\mathrm{II})$ precursor in one shot and the increase of reaction temperature to $95^{\circ} \mathrm{C}$, and (D) the introduction of $9 \mathrm{mg}$ of $\mathrm{Pt}(\mathrm{II})$ precursor. 


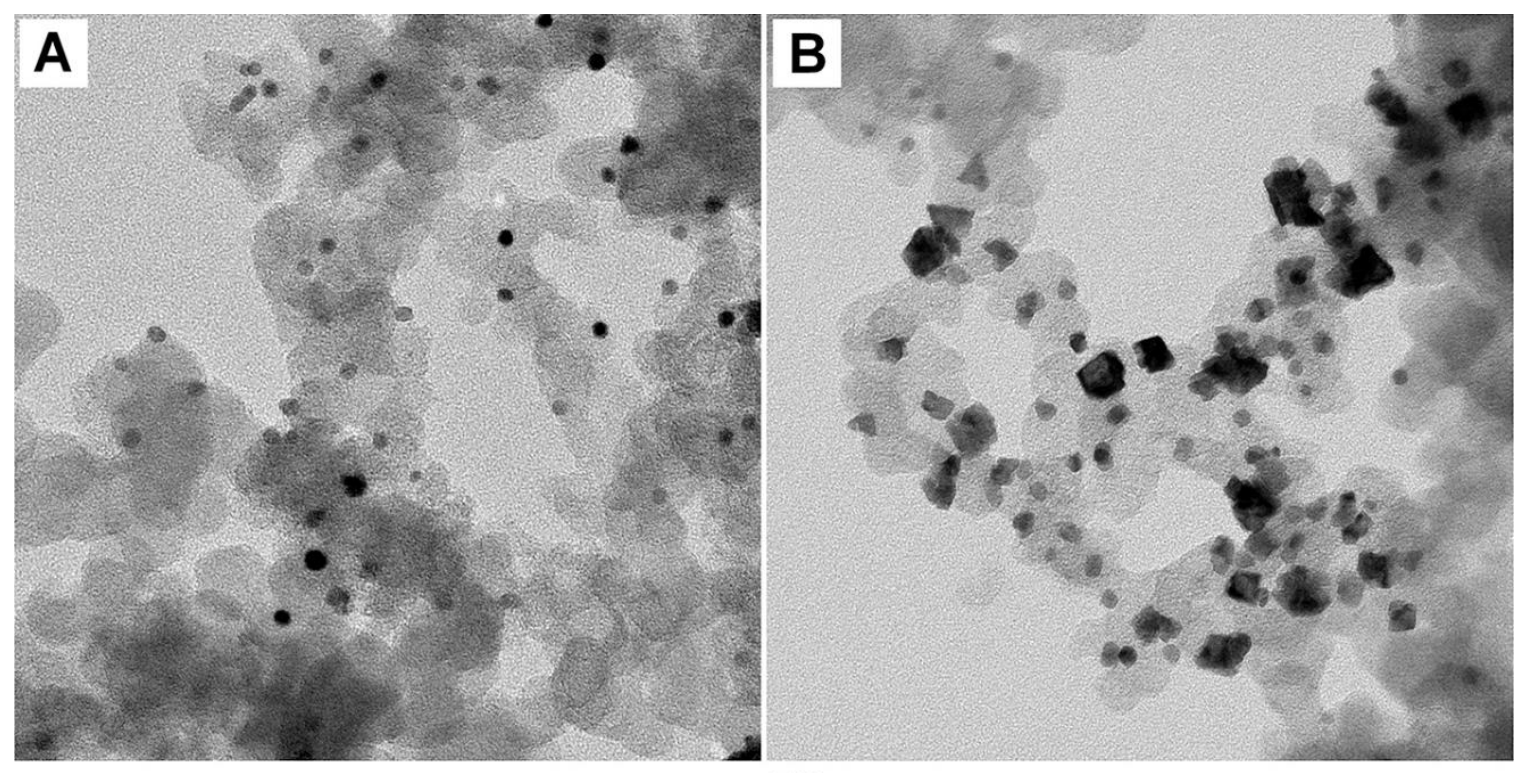

$50 \mathrm{~nm}$

Figure S10. TEM images of the samples prepared using the standard protocol except for the introduction of different amounts of citric acid: (A) 10 and (B) $60 \mathrm{mg}$, respectively. 


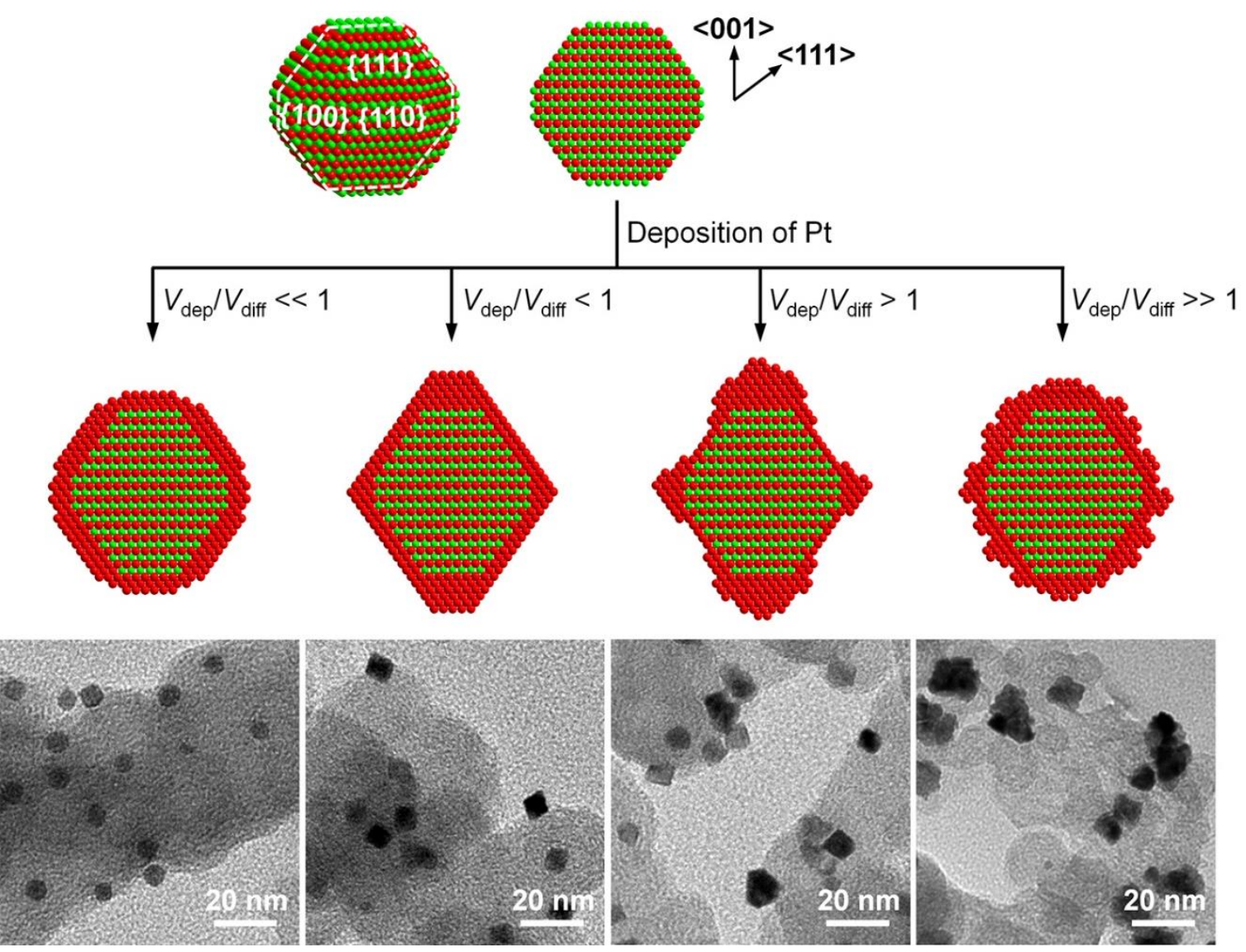

Figure S11. Schematic illustrations summarizing the different conditions and the corresponding morphology expected for the deposition of Pt on an $f c t$-Pt-Co nanocrystal seed. 


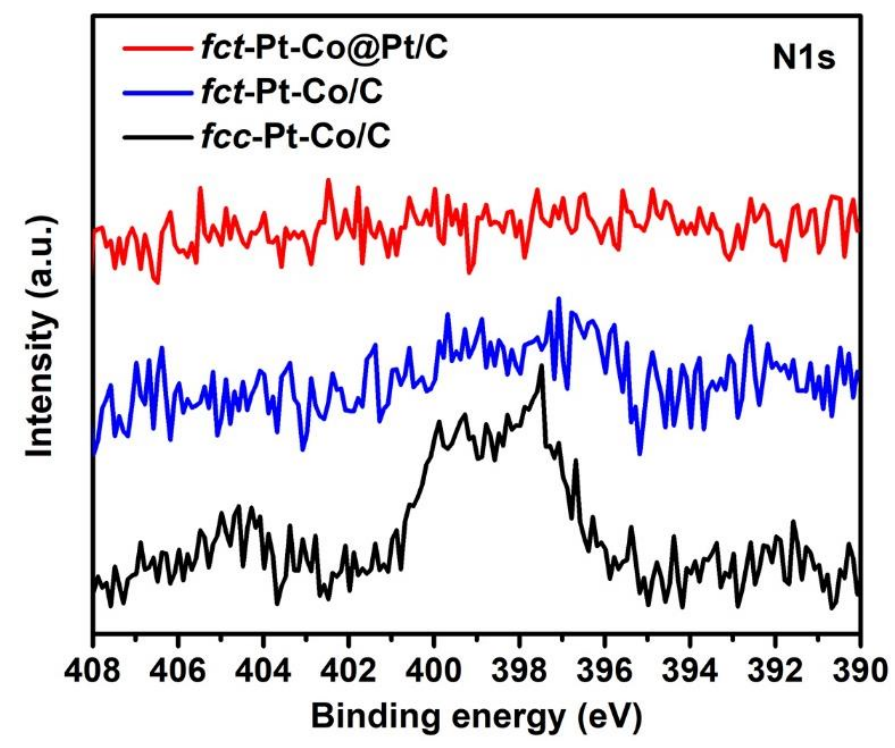

Figure S12. N 1s XPS spectra of $f c c-\mathrm{Pt}-\mathrm{Co} / \mathrm{C}, f c t-\mathrm{Pt}-\mathrm{Co} / \mathrm{C}$, and $f c t-\mathrm{Pt}-\mathrm{Co} @ \mathrm{Pt} / \mathrm{C}$, respectively. 


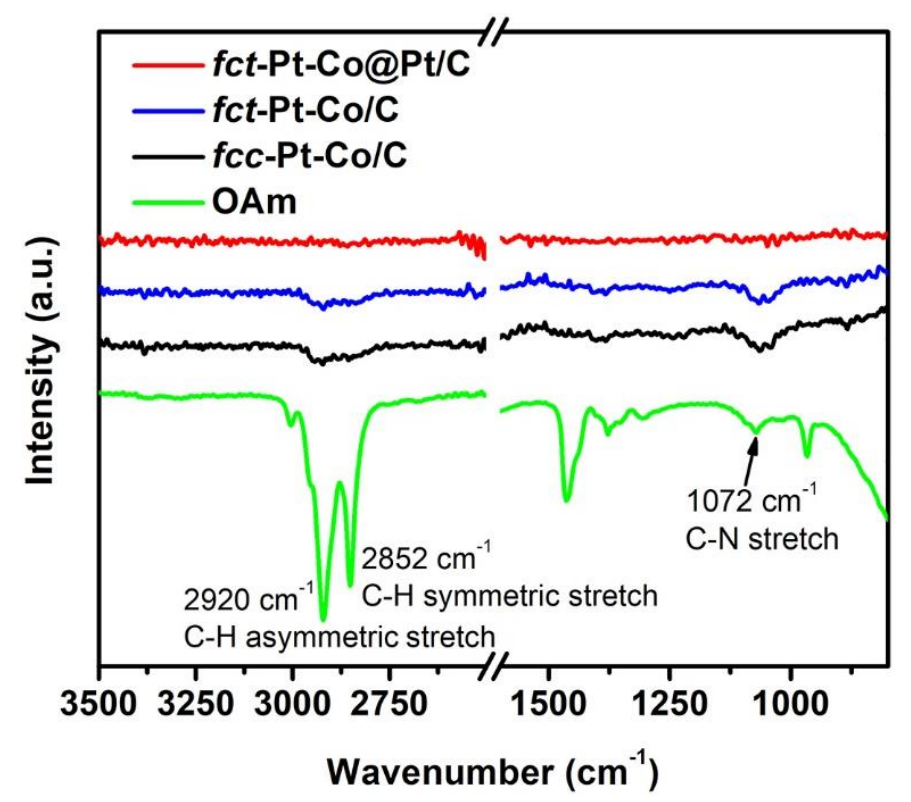

Figure S13. FTIR of the $f c c-\mathrm{Pt}-\mathrm{Co} / \mathrm{C}, f c t-\mathrm{Pt}-\mathrm{Co} / \mathrm{C}, f c t-\mathrm{Pt}-\mathrm{Co} @ \mathrm{Pt} / \mathrm{C}$, and OAm respectively. The peaks at 2920 and $2852 \mathrm{~cm}^{-1}$ could be indexed to $\mathrm{C}-\mathrm{H}$ stretch vibration of OAm while the peak at $1072 \mathrm{~cm}^{-1}$ could be assigned to the $\mathrm{C}-\mathrm{N}$ stretch vibration of $\mathrm{OAm}$. 

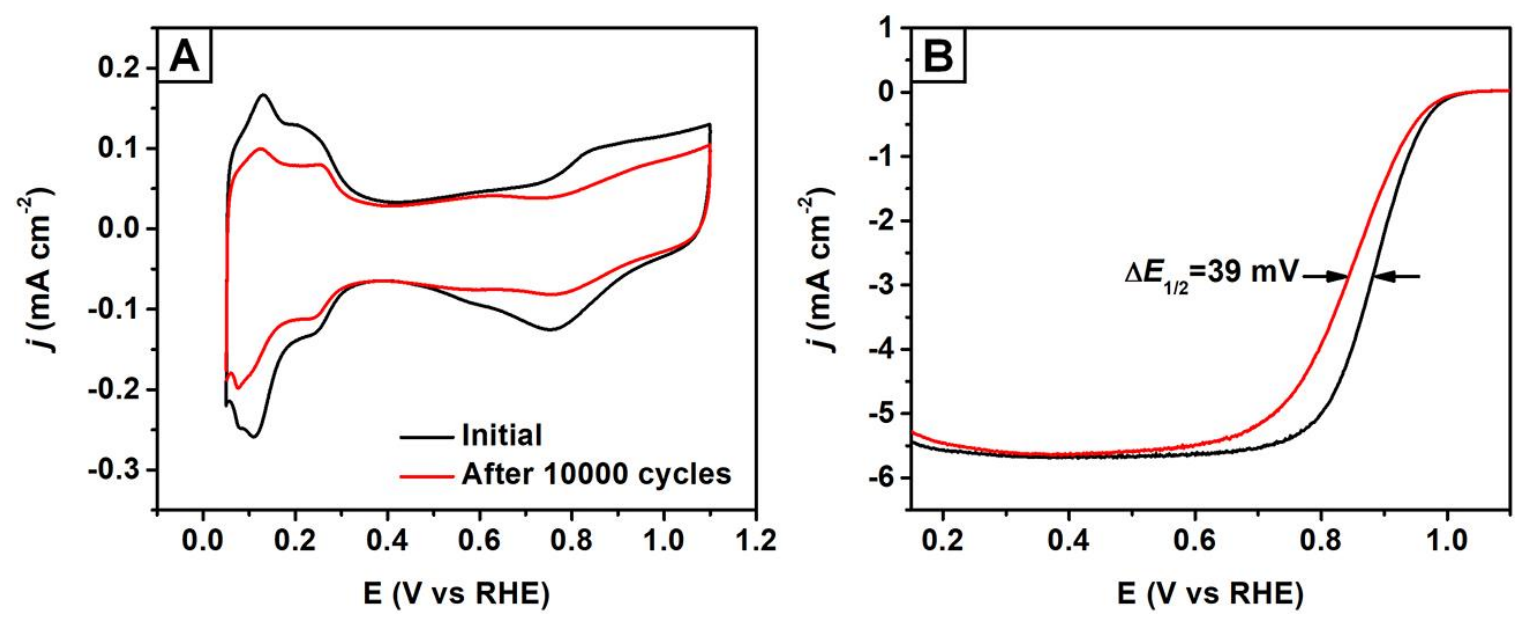

Figure S14. (A) CV and (B) ORR polarization curves recorded from the commercial Pt/C before and after different cycles of ADT. The currents were normalized to the geometric area of the rotating disk electrode. 

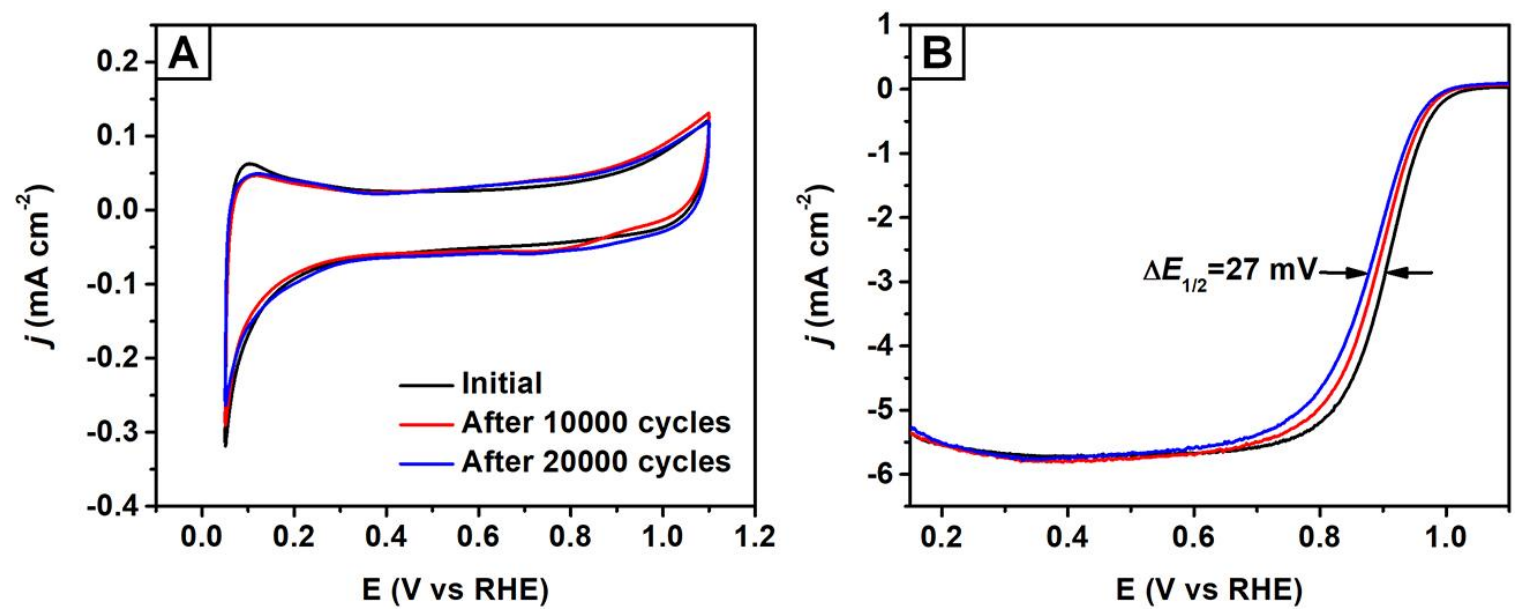

Figure S15. (A) CV and (B) ORR polarization curves recorded from the $f c c$-Pt-Co/C before and after different cycles of ADT. The currents were normalized to the geometric area of the rotating disk electrode. 

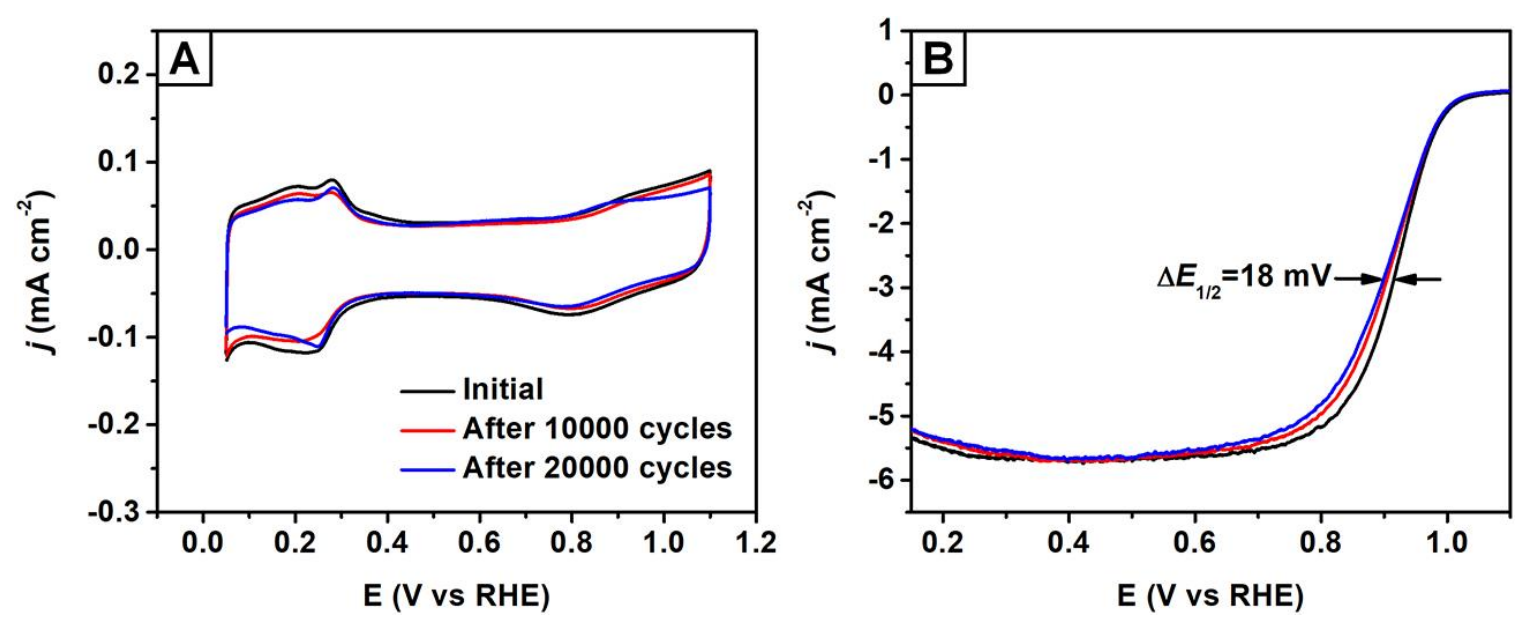

Figure S16. (A) CV and (B) ORR polarization curves recorded from the $f c t$-Pt-Co/C before and after different cycles of ADT. The currents were normalized to the geometric area of the rotating disk electrode. 


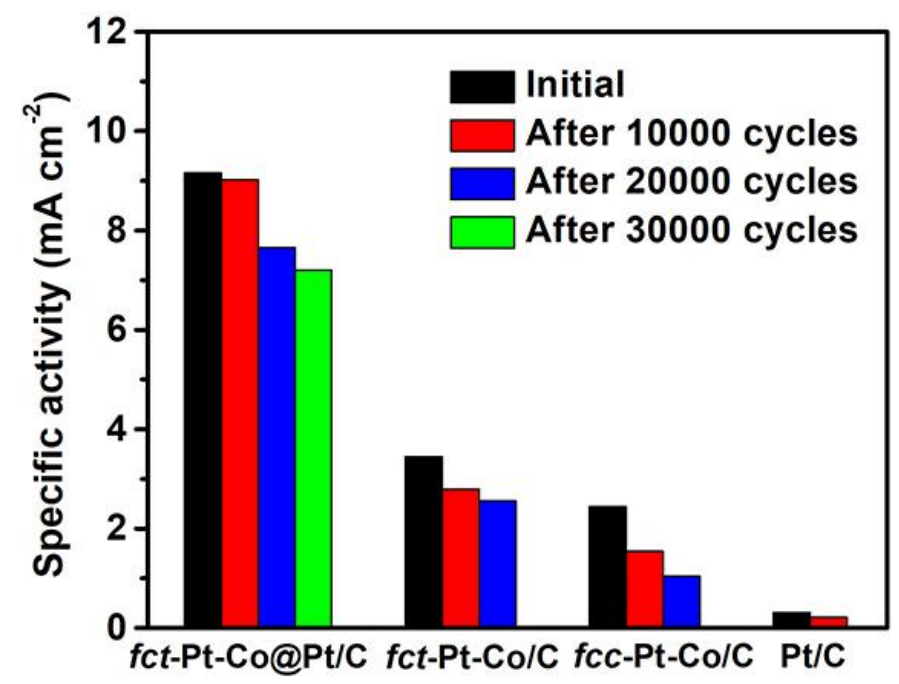

Figure S17. Specific activity of the catalysts at $0.9 \mathrm{~V}_{\mathrm{RHE}}$ before and after different cycles of ADT. 

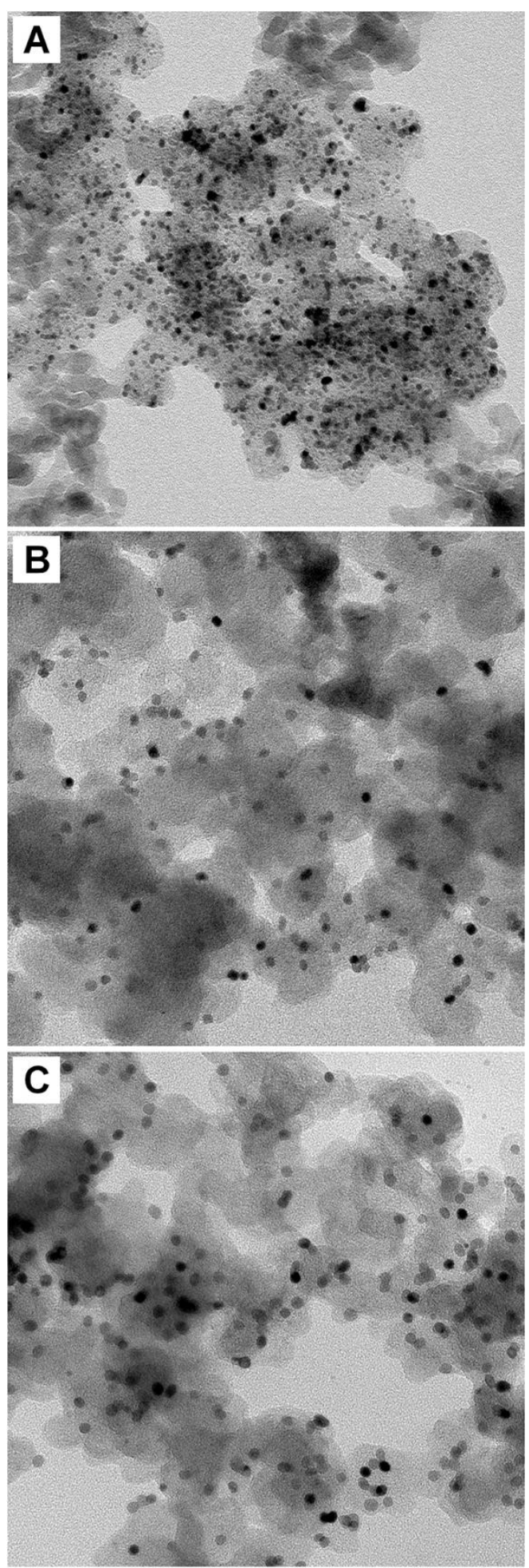

$50 \mathrm{~nm}$

Figure S18. TEM image of the (A) commercial Pt/C catalyst after 10,000 cycles of ADT, and (B) $f c c-\mathrm{Pt}-\mathrm{Co} / \mathrm{C}$ and (C) $f c t-\mathrm{Pt}-\mathrm{Co} / \mathrm{C}$ after 20,000 cycles of ADT, respectively. 

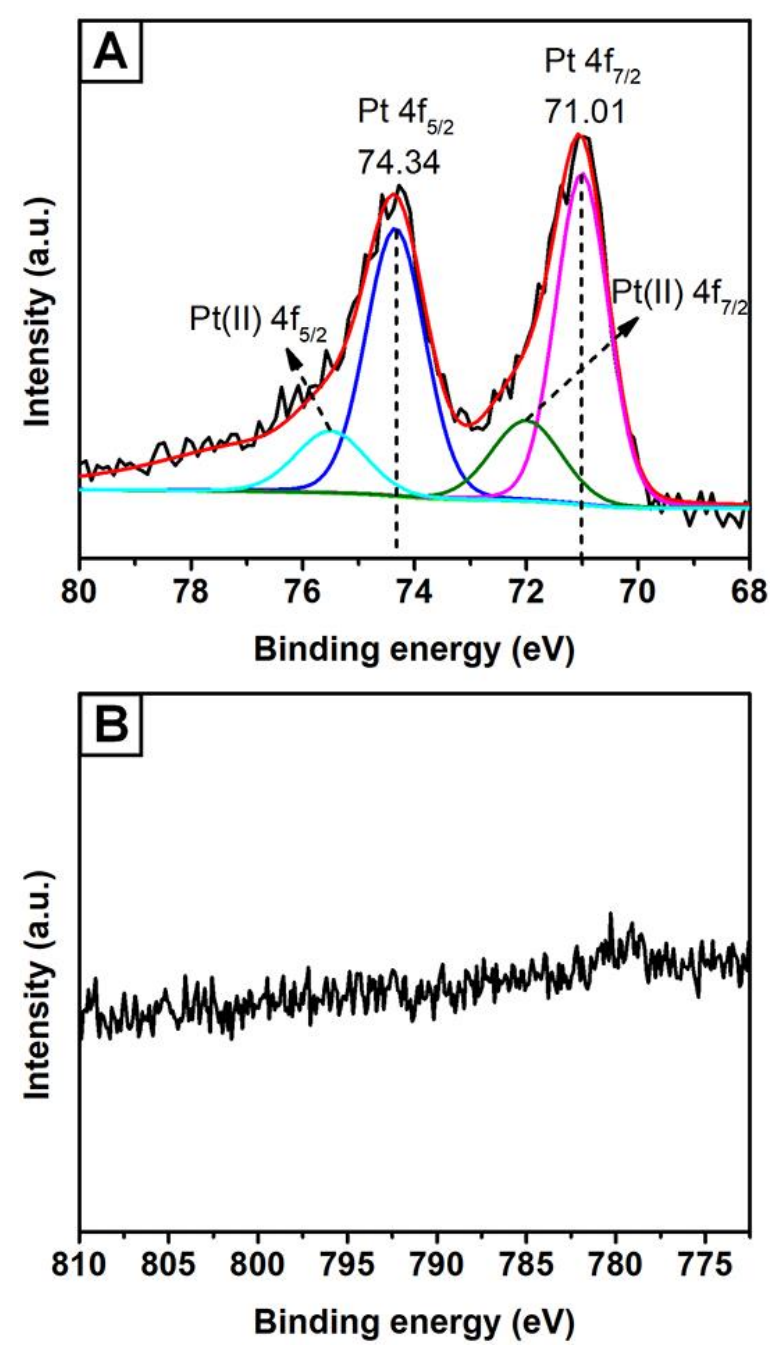

Figure S19. XPS spectra of the (A) Pt $4 \mathrm{f}$ and (B) Co $2 p$ for the $f c c-\mathrm{Pt}-\mathrm{Co} / \mathrm{C}$ after 20,000 cycles of ADT. 

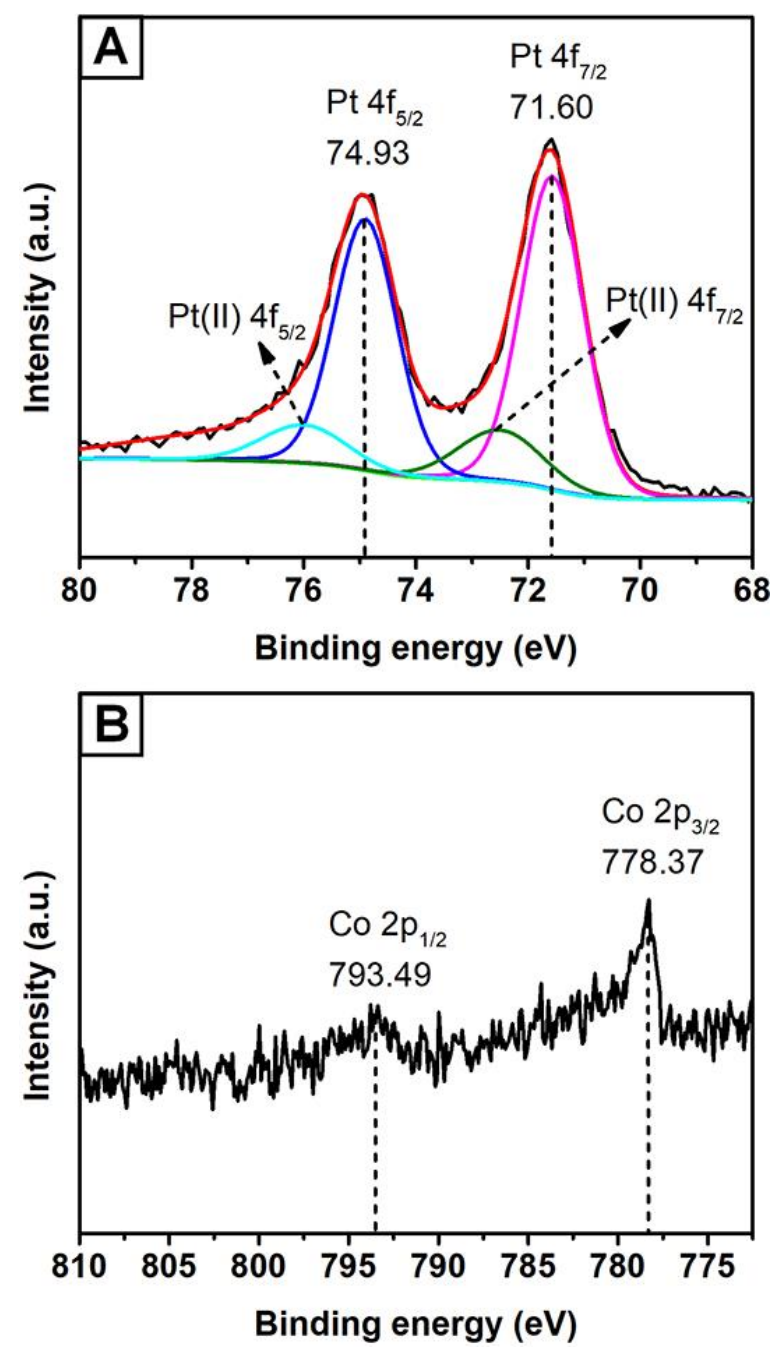

Figure S20. XPS spectra of the (A) Pt $4 \mathrm{f}$ and (B) Co $2 p$ for the $f c t-\mathrm{Pt}-\mathrm{Co} / \mathrm{C}$ after 20,000 cycles of ADT. 

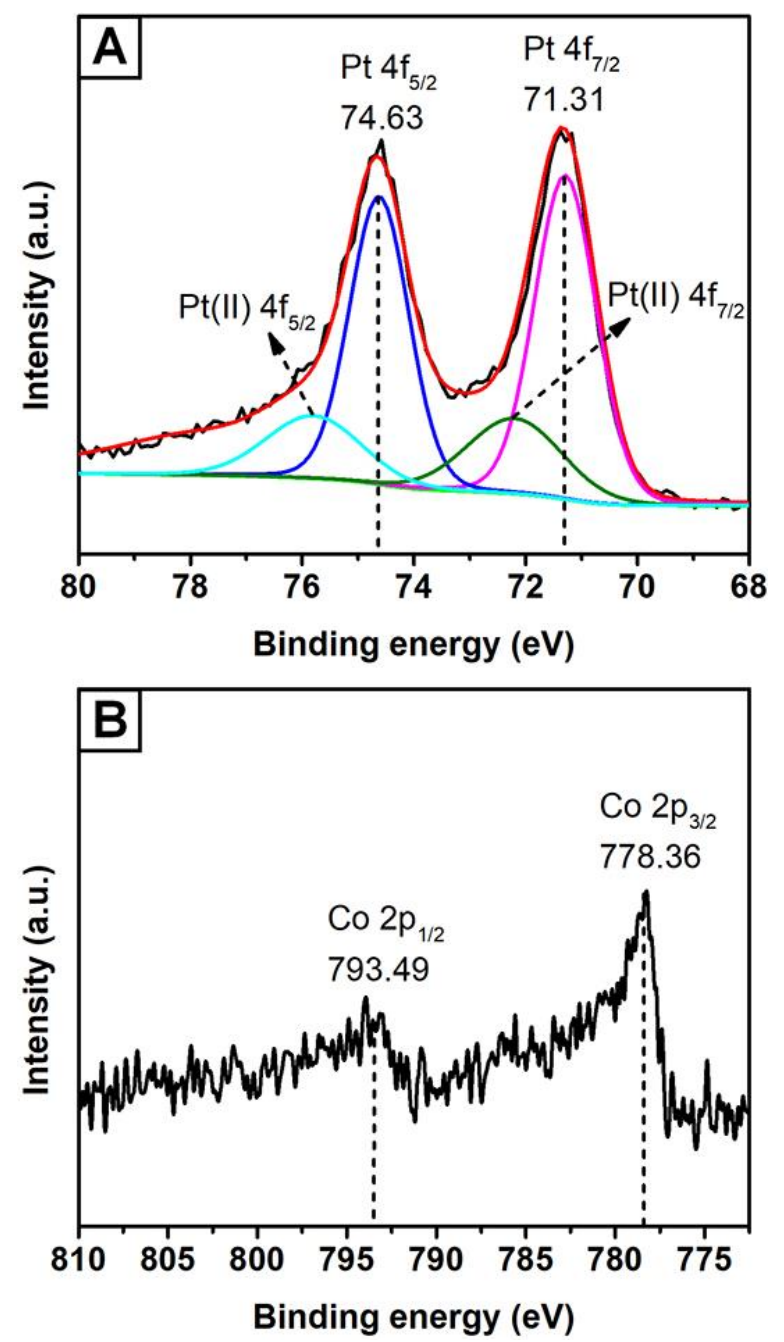

Figure S21. XPS spectra of the (A) Pt 4f and (B) Co 2p for the $f c t-\mathrm{Pt}-\mathrm{Co} @ \mathrm{Pt} / \mathrm{C}$ after 30,000 cycles of ADT. 


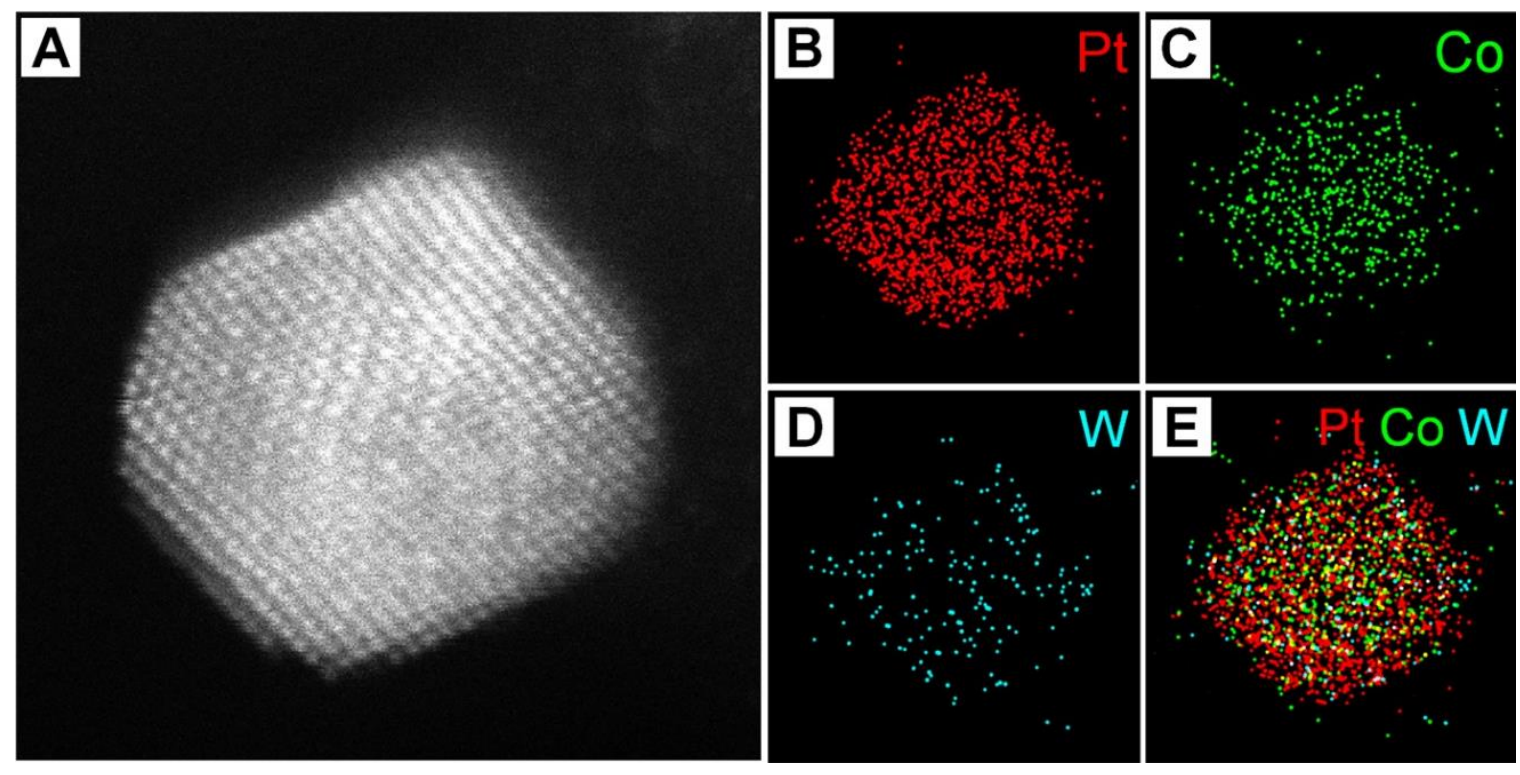

Figure S22. (A) HAADF-STEM image and (B-E) EDX mapping of an $f c t$-Pt-Co@Pt octahedral nanocrystal after 30,000 cycles of ADT: Pt (red), Co (green), and W (cyan). 
Table S1. Comparison of the compositions of $f c c-\mathrm{Pt}-\mathrm{Co} / \mathrm{C}, f c t-\mathrm{Pt}-\mathrm{Co} / \mathrm{C}$, and $f c t-\mathrm{Pt}-\mathrm{Co} @ \mathrm{Pt} / \mathrm{C}$, as well as the catalysts after ADT. The atomic ratios were determined using ICP-MS.

\begin{tabular}{lll}
\hline Sample & $\mathrm{Pt}$ & $\mathrm{Co}$ \\
\hline$f c c-\mathrm{Pt}-\mathrm{Co} / \mathrm{C}$ & $41 \%$ & $59 \%$ \\
$f c t-\mathrm{Pt}-\mathrm{Co} / \mathrm{C}$ & $41 \%$ & $59 \%$ \\
$f c t-\mathrm{Pt}-\mathrm{Co} @ \mathrm{Pt} / \mathrm{C}$ & $54 \%$ & $46 \%$ \\
$f c c-\mathrm{Pt}-\mathrm{Co} / \mathrm{C}$ after ADT & $89 \%$ & $11 \%$ \\
$f c t-\mathrm{Pt}-\mathrm{Co} / \mathrm{C}$ after ADT & $66 \%$ & $34 \%$ \\
$f c t-\mathrm{Pt}-\mathrm{Co} @ \mathrm{Pt} / \mathrm{C}$ after ADT & $61 \%$ & $39 \%$ \\
\hline
\end{tabular}


Table S2. Comparison of the XRD data of $f c c-\mathrm{Pt}-\mathrm{Co} / \mathrm{C}, f c t-\mathrm{Pt}-\mathrm{Co} / \mathrm{C}$, and $f c t-\mathrm{Pt}-\mathrm{Co} @ \mathrm{Pt} / \mathrm{C}$.

\begin{tabular}{llll}
\hline Sample & $\begin{array}{l}(111) \text { peak at } 2 \theta \\
(\text { degree })\end{array}$ & $\begin{array}{l}\text { Approximate Pt percent } \\
\text { according to Vegard's law }\end{array}$ & $\begin{array}{l}\text { lattice parameters } \\
(\AA)\end{array}$ \\
\hline$f c c-\mathrm{Pt}-\mathrm{Co} / \mathrm{C}$ & 40.49 & $82 \%$ & $a=b=c=3.85$ \\
$f_{c t}$-Pt-Co/C & 41.43 & $59 \%$ & $a=b=3.79, c=3.70$ \\
$f c t-\mathrm{Pt}-\mathrm{Co} @ \mathrm{Pt} / \mathrm{C}$ & 41.02 & $68 \%$ & $a=b=3.81, c=3.74$ \\
\hline
\end{tabular}


Table S3. Comparison of ORR activity and durability of the 8-nm $f c t-\mathrm{Pt}-\mathrm{Co} @ \mathrm{Pt} / \mathrm{C}$ catalyst described in this work with the representative Pt-Co catalysts reported in the literature.

\begin{tabular}{|c|c|c|c|c|c|}
\hline Catalyst & $\begin{array}{l}\text { Specific ECSA } \\
\left(\mathrm{m}^{2} \mathrm{~g}_{\mathrm{Pt}}^{-1}\right)\end{array}$ & $\begin{array}{l}\text { SA at } 0.9 \mathrm{~V} \\
\left(\mathrm{~mA} \mathrm{~cm}^{-2}\right)\end{array}$ & $\begin{array}{l}\text { MA at } 0.9 \mathrm{~V} \\
\left(\mathrm{~A} \mathrm{mgt}_{\mathrm{Pt}}^{-1}\right)\end{array}$ & $\begin{array}{l}\text { MA loss after } \\
\text { ADT }(\%)\end{array}$ & Reference \\
\hline $\begin{array}{l}\text { 8-nm } f c t-\mathrm{Pt}-\mathrm{Co} @ \mathrm{Pt} \\
\text { octahedra }\end{array}$ & 31 & 9.16 & 2.82 & $20.9(30 \mathrm{k})$ & This work \\
\hline $\begin{array}{l}\text { 9-nm L1 } 1_{0}-\mathrm{PtCo} \\
\text { nanoparticles }\end{array}$ & 27 & 8.26 & 2.26 & $19.7(30 \mathrm{k})$ & (1) \\
\hline $\begin{array}{l}\text { 3-nm L10-W-PtCo } \\
\text { nanoparticles }\end{array}$ & 61 & 3.60 & 2.21 & 7.7 (10k) & (2) \\
\hline $\begin{array}{l}\text { Pt-skin } \mathrm{Pt}_{3} \mathrm{Co} \\
\text { z-nanowires }\end{array}$ & 39 & 5.60 & 2.20 & $22.3(50 \mathrm{k})$ & (3) \\
\hline 4-nm $\mathrm{Pt}_{75} \mathrm{Co}_{25} / \mathrm{C}$ & 50 & 2.06 & 0.97 & & (4) \\
\hline 5-nm PtCo nanocubes & 183 & 0.52 & 0.95 & & $(5)$ \\
\hline $\mathrm{Au}$-doped $\mathrm{Pt}-\mathrm{Co} / \mathrm{C}$ & 44 & 1.85 & 0.81 & $62.1(10 \mathrm{k})$ & (6) \\
\hline $\begin{array}{l}\text { Au-doped } \mathrm{L}_{0} \mathrm{Pt}-\mathrm{Co} \\
\text { nanoparticles }\end{array}$ & 128 & 0.53 & 0.68 & $5.5(10 \mathrm{k})$ & (7) \\
\hline $\begin{array}{l}\text { Intermetallic } \mathrm{Pt}_{3} \mathrm{Co} \\
\text { nanoparticles }\end{array}$ & 47 & 1.10 & 0.52 & & (8) \\
\hline $\begin{array}{l}\text { Pt-Co excavated } \\
\text { octahedra }\end{array}$ & 19 & 1.85 & 0.35 & & (9) \\
\hline 2.5-nm Pt-Co@Pt/C & 71 & 0.472 & 0.34 & $44.4(30 \mathrm{k})$ & $(10)$ \\
\hline
\end{tabular}


Table S4. Comparison of the EDX data of $f c t-\mathrm{Pt}-\mathrm{Co} @ \mathrm{Pt} / \mathrm{C}$ before and after 30,000 cycles of ADT. The atomic ratios were based on Pt L, Co K, and W L.

\begin{tabular}{llll}
\hline Sample & Pt & Co & W \\
\hline$f c t$-Pt-Co@Pt/C & $59.9 \%$ & $37.9 \%$ & $2.2 \%$ \\
$f c t$-Pt-Co@Pt/C after ADT & $65.9 \%$ & $32.9 \%$ & $1.2 \%$ \\
\hline
\end{tabular}




\section{REFERENCES}

(1) Li, J.; Sharma, S.; Liu, X.; Pan, Y.; Spendelow, J. S.; Chi, M.; Jia, Y.; Zhang, P.; Cullen, D. A.; Xi, Z.; Lin, H.; Yin, Z.; Shen, B.; Muzzio, M.; Yu, C.; Kim, Y. S.; Peterson, A. A.; More, K. L.; Zhu, H.; Sun, S. Hard-Magnet L10-CoPt Nanoparticles Advance Fuel Cell Catalysis. Joule 2019, $3,124-135$.

(2) Liang, J.; Li, N.; Zhao, Z.; Ma, L.; Wang, X.; Li, S.; Liu, X.; Wang, T.; Du, Y.; Lu, G.; Han, J.; Huang, Y.; Su, D.; Li, Q. Tungsten-Doped L1 $1_{0}$ PtCo Ultrasmall Nanoparticles as a High-Performance Fuel Cell Cathode. Angew. Chem. Int. Ed. 2019, 58, 15471-15477.

(3) Luo, M.; Sun, Y.; Qin, Y.; Chen, S.; Li, Y.; Li, C.; Yang, Y.; Wu, D.; Xu, N.; Xing, Y.; Wang, L.; Gao, P.; Guo, S. Surface and Near-Surface Engineering of PtCo Nanowires at Atomic Scale for Enhanced Electrochemical Sensing and Catalysis. Chem. Mater. 2018, 30, 6660-6667.

(4) Choi, D. S.; Robertson, A. W.; Warner, J. H.; Kim, S. O.; Kim, H. Low-Temperature Chemical Vapor Deposition Synthesis of Pt-Co Alloyed Nanoparticles with Enhanced Oxygen Reduction Reaction Catalysis. Adv. Mater. 2016, 28, 7115-7122.

(5) He, C.; Zhang, S.; Tao, J.; Shen, P. One-Step Solid State Synthesis of PtCo Nanocubes/Graphene Nanocomposites as Advanced Oxygen Reduction Reaction Electrocatalysts. J. Catal. 2018, 362, 85-93.

(6) Choi, J.; Cho, J.; Roh, C. W.; Kim, B. S.; Choi, M. S.; Jeong, H.; Ham, H. C.; Lee, H. Au-Doped PtCo/C Catalyst Preventing Co Leaching for Proton Exchange Membrane Fuel Cells. Appl. Catal. B-Environ. 2019, 247, 142-149.

(7) Kuttiyiel, K. A.; Kattel, S.; Cheng, S.; Lee, J. H.; Wu, L.; Zhu, Y.; Park, G. G.; Liu, P.; Sasaki, K.; Chen, J. G.; Adzic, R. R. Au-Doped Stable L1 ${ }_{0}$ Structured Platinum Cobalt Ordered Intermetallic Nanoparticle Catalysts for Enhanced Electrocatalysis. ACS Appl. Energ. Mater. 2018, 1, 3771-3777.

(8) Wang, D.; Xin, H. L.; Hovden, R.; Wang, H.; Yu, Y.; Muller, D. A.; DiSalvo, F. J.; Abruna, H. D. Structurally Ordered Intermetallic Platinum-Cobalt Core-Shell Nanoparticles with Enhanced Activity and Stability as Oxygen Reduction Electrocatalysts. Nat. Mater. 2013, 12, 81-87. 
(9) Chen, Q.; Cao, Z.; Du, G.; Kuang, Q.; Huang, J.; Xie, Z.; Zheng, L. Excavated Octahedral Pt-Co Alloy Nanocrystals Built with Ultrathin Nanosheets as Superior Multifunctional Electrocatalysts for Energy Conversion Applications. Nano Energy 2017, 39, 582-589.

(10) Lee, S.; Jang, J. H.; Jang, I.; Choi, D.; Lee, K. S.; Ahn, D.; Kang, Y. S.; Park, H. Y.; Yoo, S. J. Development of Robust Pt Shell through Organic Hydride Donor in PtCo@Pt Core-Shell Electrocatalysts for Highly Stable Proton Exchange Membrane Fuel Cells. J. Catal. 2019, 379, $112-120$. 